\title{
Extent of Empowerment of Employed Women through Employment
}

\author{
Priyanka $^{1}$, A. S. Tigga ${ }^{1}$ and Dhananjay Kumar ${ }^{2}$ \\ ${ }^{1}$ Department of Extension Education, Bihar Agricultural University, Sabour, Bhagalpur, India \\ ${ }^{2}$ Department of Soil Science and Agricultural Chemistry, Bihar Agricultural University, \\ Sabour, Bhagalpur, India \\ *Corresponding author
}

\section{A B S T R A C T}

\section{Keywords}

Employment,

Empowerment,

Economic

empowerment,

Decision making,

Employed women

Article Info

Accepted:

20 January 2020

Available Online:

10 February 2020
The role of employed women has changed throughout the country and the world due to economic conditions and social demands. It has found in a scenario in which married employed women have tremendous pressure to develop their career as robust as their male counterparts while sustaining active engagement in personal life. Economic empowerment is the capacity of women to participate in, contribute to and benefit from growth process in ways which recognise the value of their contribution, respect their dignity and make it possible to negotiate a fairer distribution of the benefits of growth. In the economic sphere, paid employment is seen as essential to women's empowerment which focuses on access to employment opportunities and working conditions at work place and at community level, and on a woman's decision making power and contribution to total family earnings in the household. This paper is an attempt to know the extent of empowerment of employed women through employment. It was measured by one of the indicators of women empowerment that is "decision making". The statistical tools used for the study and data were subjected to descriptive statistics. It also concluded that there are number of structural barriers which limit the extent of empowerment.

\section{Introduction}

Where women are generally denied the ownership of property and control over assets, the ability to earn outside income can become an important instrument for the transformation of gender relations and challenge many traditional modes of social and economic relations (UNESCAP report, 1999).
Empowerment of women has been recognized as a central issue in determining the status of women. Empowerment covers aspects such as women's control over material and intellectual resources. Empowerment is a process, not an event, which challenges traditional power equations and relations. Abolition of genderbased discrimination in all institutions and structures of the society and participation of 
women in policy and decision-making processes at domestic and public levels are few dimensions of women empowerment. Empowerment of women is not a one process. It is a two-way process in which we empower and get empowered in turn. Empowerment implies power. This may be broadly defined as control over material assets, intellectual resources and ideology.

Women's empowerment in India principally aims at enhancing their social functioning by a quantitative and qualitative change, particularly in the field of educating health and employment. Redistribution of social power and a change in the control of resources in favour of women in any society is not possible unless they are healthy, educated and provided with some gainful employment opportunities (Goswami, 2013). Empowerment of women consist of greater access to knowledge and resources, greater autonomy in decision making to enable them to have greater ability to plan their lives, or to have greater control over the circumstances that influence their lives and free from shocks imposed on them by custom, belief and practice (GU, 2005).Research on women's status in developing countries reports widespread inequality between the genders. Inequality between women and men takes the form of economic inequality as well as differentials in education, health care, rights and access to a number of essential resources and differences in power in all spheres of life. Women's empowerment in terms of the ability to exercise control over their lives, control over their labor, freedom to move and interact, access to leadership position and control over reproduction (Rajagopalan, 2002)

Employment can be an important source of empowerment for women, particularly for cash and in the formal sector. Employment empowers women by providing financial independence, alternative source of social identity and exposure to power structures. It makes one confident in mastering the job situation and increases competence, i.e. better skill in performing a given task or a number of tasks. It makes one independent because confidence, competence and awareness makes one to decide on one's judgment, and finally, it makes one critical, to ask and raise questions, able to make differences between what is right and what is not wrong.

Economic empowerment of women is the key to gender equality and well being of a nation. This would not only enhance women's capacity of decision making but also lead to reduction in corruption, armed conflict and violence against females in the long run (Blumberg, 2005).

Women's household decision-making and freedom of movement are often used as indicators of women's empowerment. The ability to make decisions that affect one's life and the ability to move beyond the sphere of the home freely exemplify autonomy and were quickly adopted as basics to empowerment. Other aspects of women's lives have become important to empowerment as the concept has expanded to encompass power in a number of spheres and forms.

When there are positive impacts on empowerment and market activity affects women's ability to influence resource allocation and domestic decision-making (Acharya et al., 1983), drastic changes in women's .empowerment as a result of employment are limited. It is argued that simply being employed is probably not enough to ensure women's empowerment because working does not necessarily allow women to challenge the power structures that prevent their agency and full participation in society.

\section{Materials and Methods}

The study was carried out in Sabour block of 
Bhagalpur district in Bihar in 2017. The proximity of the locale from the university headquarters and an advance rapport with the population environment was expected to facilitate in the interview of the respondent effectively. In addition to this, in order to delineate the conducting real empowerment of women due to their employment in different government sectors.

The reason behind to take Sabour block for the study was due to the availability of five types of respondent these are Assistant professor, Doctors, Nurses, Teachers, Bankers who has to see the empowerment of women through employment and then five types of respondent were employed in agriculture colleges, schools, banks, hospitals in Sabour block.

The random sampling procedure was adopted to select the respondents for the study. A sampling frame of married employed women was prepared for the study by visiting the different government sectors (i.e. Schools, colleges, banks and a hospital) of employed women. A sample of 100 married employed women was selected randomly. Since the focus of the study was to find out the empowerment of the employed women.

\section{Results and Discussion}

Empowerment of employed women was measured by one of the indicators i.e. decision making. The results have been presented in Table $1 \& 2$.

\section{Decision making}

To explore the changes in decision making pattern of women due to employment responses of the respondents were obtained under three categories: independently, jointly with husband, husband only.
The results in Table 1 indicated that majority of respondents were taking independent decision regarding purchasing for self (62.00 $\%)$ and purchasing daily household items $(57.00 \%)$. Whereas decision regarding obtaining health care ( $82.00 \%)$, staying with family $(91.00 \%)$, going for outings $(83.00 \%)$, purchasing for children ( $65.00 \%$ ), children education $(57.00 \%)$, children marriage $(95.00$ $\%$ ), household expenditure (61.00\%), house repair and construction (56.00\%), and equal treatments for girls and boys in the family were taken jointly with husband.

The present findings were in line with the findings of Hillenbrand (2012), who observed that two-thirds of women $(65.00 \%)$ said that husbands alone made decisions about women's health care and 32.00 per cent alone made decisions about the child health care. Just 5.00 per cent of women said that they could solely control their own earnings and 5.00 per cent also said that they had independent say over other household decisions. Further it was found that women had least autonomy when it comes to make household purchases with less than 1.00 per cent of women claimed that they could make such decisions on their own.

\section{Level of decision making}

Level of decision making pattern of the respondents was categories into low, medium, high on the basis of Mean \pm S.D. The result has been shown in Table 2 .

The data depicted in Table 2 revealed that 81.00 per cent of respondents were found in the medium level of decision making followed by 13.00 per cent respondents were found in the low level of decision making and only 6.00 per cent respondents were found in high level of decision making which is pictorially clear from fig no.1. 
Table.1 Distribution of the respondents according to decision making

\begin{tabular}{|c|c|c|c|c|}
\hline \multirow[b]{3}{*}{ Sr.No. } & \multirow[b]{3}{*}{ Aspects } & \multicolumn{3}{|c|}{ Total $(n=100)$} \\
\hline & & \multicolumn{3}{|c|}{ Per cent } \\
\hline & & Independent & $\begin{array}{c}\text { Jointly with } \\
\text { husband }\end{array}$ & $\begin{array}{l}\text { Husband } \\
\text { only }\end{array}$ \\
\hline 1. & Obtaining health care & 17 & 82 & 1 \\
\hline 2. & Staying with family & 9 & 91 & 0 \\
\hline 3. & Going for outings & 17 & 83 & 0 \\
\hline 4. & Purchasing for children & 35 & 65 & 0 \\
\hline 5. & Purchasing for self & 62 & 37 & 1 \\
\hline 6. & Purchasing daily household items & 57 & 39 & 4 \\
\hline 7. & Children's education & 34 & 57 & 9 \\
\hline 8. & Children's marriage & 4 & 95 & 1 \\
\hline 9. & Household expenditure & 39 & 61 & 0 \\
\hline 10. & House repair and construction & 6 & 56 & 38 \\
\hline 11. & $\begin{array}{l}\text { Equal treatment for girls and boys in } \\
\text { the family }\end{array}$ & 8 & 92 & 0 \\
\hline
\end{tabular}

Table.2 Level of decision making pattern of the respondents

\begin{tabular}{|c|c|c|}
\hline & \multicolumn{2}{|c|}{ Total $(\mathbf{n}=\mathbf{1 0 0})$} \\
\hline Sr. No. & Category & Per cent \\
\hline 1. & Low $(<21.65)$ & 13 \\
\hline 2. & Medium $(21.65-27.02)$ & 81 \\
\hline 3. & High $(>27.02)$ & 6 \\
\hline & Mean $=\mathbf{2 4 . 3 4}$ & S.D $=\mathbf{2 . 6 8}$ \\
\hline
\end{tabular}

Fig.1 Level of decision making pattern of the respondents

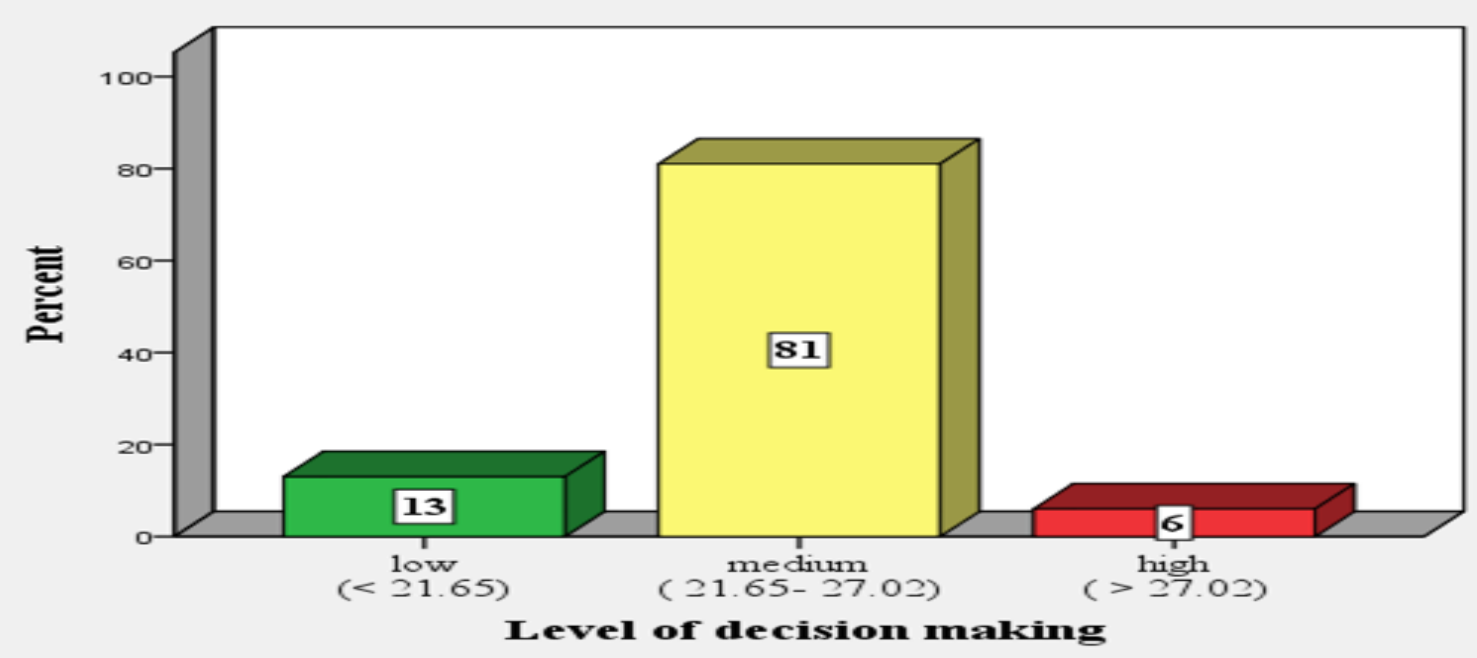


Haque et al., (2011) found the level of women empowerment in decision making (both economic and household) as satisfactory but the empowerment in physical movement was very low and overall empowerment level of women in Bangladesh was the least.

In conclusion, the level of decision making of the employed women was found medium $(81.00 \%)$ it means there is still need of employed women to empower. It is clearly evident from the result that employment is important to empowerment and that women who work have a greater likelihood of higher empowerment than those women that do not, but that the strength of the relationship varies by empowerment indicator. This paper also demonstrates that employment can play an important role in the process of improving women's empowerment in India, there are numerous barriers to overcome, and employment, even under all the right conditions. We cannot forget that empowerment a state of being as well as state of mind and before full empowerment can be realized, women need to not only act differently, but to think differently, to value themselves more, and to really believe that they are equal. In order for employment to be more empowering to women and for women's empowerment in India to be facilitated in general, the structural barriers to women's rights and equality must be addressed in the household, the community, the state, the nation and around the globe.

\section{References}

Acharya, Meena, and Lynn Bennett .1983. Women and the Subsistence Sector:
Economic Participation and Household Decision-making in Nepal. Working Paper Number 526. Washington: World Bank.

Blumberg. 2005 in Devi, U. 2014. Impact of Employment on Women Empowerment. Unpublished M.Sc.(Ag.) Thesis, CCS Haryana Agricultural University, Hisar, Haryana, India.

Goswami. 2013. in Sabanna, Y. 2016. Women Empowerment in India Some Issues. Global Journal for Research Analysis, 5(7): 218-219.

GU, B. 2005. Empowerment of Rural Women through Income Generating Activities in Gadag District on Northern Karnataka. Unpublished M.Sc. Thesis, University of Agricultural Sciences, Bangalore.

Haque, M. M., Islam, T. M., Tareque, M. I., \& Mostofa, M. G. 2011.Women Empowerment or Autonomy: A Comparative View in Bangladesh Context. Bangladesh e-Journal of Sociology, 8: 17

Hillenbrand, E. 2012. Baseline Gender Disparities Relevant to a Nutrition Education Strategy in Rural Bangladesh. Retrieved from http://www.ipcbee.com/vol39/011ICNFS2012-N019.pdf, on 13/06/2017.

Rajagopalan. 2002. in Devi, U. 2014. Impact of Employment on Women Empowerment. Unpublished M.Sc. (Ag.) Thesis, CCS Haryana Agricultural University, Hisar, Haryana, India.

UNESCAP. 1999. "Emerging Issues and Developments at the Regional Level: Socio-Economic Measures To Alleviate Poverty In Rural And Urban Areas." E/ESCAP/1133, February 18, 1999.

\section{How to cite this article:}

Priyanka, A. S. Tigga and Dhananjay Kumar. 2020. Extent of Empowerment of Employed Women through Employment. Int.J.Curr.Microbiol.App.Sci. 9(02): 2997-3001. doi: https://doi.org/10.20546/ijcmas.2020.902.343 